\title{
Risk typology
}

\author{
S. Zahedi
}

Allameh Tabataba'i University, Iran

\begin{abstract}
This article considers the definition of risk. Since the conceptual definition of risk varies with perspectives, some of the perspectives ranging from event-driven to financial and business risks are described. The classification of risk is explored and different types of risks are considered. In order to decrease the chance of loss, risk managers must weigh the relative costs and benefits associated with activities that give rise to risk and try to minimize the costs.
\end{abstract}

Keywords: risk definition, risk categorization, natural risks, human risks, political risks, social risks, economic risks, risk management.

\section{Introduction}

This article considers some of the definitions of risk. An argument is made for distinguishing between different perspectives in the related literature, each focusing on a particular aspect of risk. The article continues with the classification of risk and elaborates more on those types of risks where there is a greater possibility of managing them through risk management techniques.

\section{Risk definition}

There are different definitions of risk in management literature, among which are the following:

- Risk is defined as uncertainty concerning loss [1].

- Risk is any source of randomness that may have an adverse impact on a person or corporation [2].

- Risk is the combination of the frequency, or probability, of occurrence and the consequence of special hazardous events [3]. 
- $\quad$ Risk is the possibility that the positive expectations of a goal-oriented system will not be realized.

This definition, proposed by Dr. M. Haller, is a useful one for risk management purposes, because:

- It concentrates on undesired consequences;

- It accepts that positive expectations may not be expressed in monetary terms;

- It applies to every "goal-oriented systems" (an individual, a department, a company...) [4].

\section{Perspectives}

The conceptual definition of risk varies with the perspective. Some of the perspectives in the related literature are as follows.

\subsection{Event-driven definitions}

This perspective defines risk differently based on the type of event that can result in a loss. This perspective is popular with risk managers.

\subsection{Diversifiability}

This perspective, which is more popular with academics, differentiates between the risk that a firm can diversify and hedge away and the risks that it cannot.

\subsection{Financial versus business}

This perspective attempts to distinguish between financial and business risks. Financial risks are those that a firm is not in the business of bearing and this is thus a risk that firms can avoid. Business risks are those that a firm must bear in order to operate its primary business [2].

None of these perspectives are independent and due to disparity in audiences, they coexist. This means looking at the same picture from different angles and conceptualizing different perceptions from the same reality.

\section{Risk categorization}

Some of the risk categorizations are as follows:

\subsection{The first category}

The first category contains four sub-categories.

\subsubsection{Subjective and acceptable}

Subjective risk refers to the mental state of an individual and is the extent to which a person feels threatened by a particular risk. This may bear no relation to the objectively-assessed probability of its occurrence. 
Acceptable risk is the level of subjective risk which an individual or organization feels comfortable in facing [4].

\subsubsection{Pure and speculative}

Pure risks are those that present the possibility of a loss, but not a profit. There are many sources of pure risks. One way of classifying them is in relation to property, liability, health, and loss-of-income exposures.

Speculative risks may produce a profit or a loss. The boundary between the two types of risks is by no means always clear-cut, particularly in such fields as that of political risk [4].

\subsubsection{Static and dynamic}

Static risks are those that are always present in any society, such as the risks of fire and other natural perils. In another definition, static risks are those that present in an unchanging society that is in stable equilibrium [1].

Dynamic risks are those that change as society changes. Economic, political, social, legal, technological and environmental changes may all create new risks or modify existing ones [4].

\subsubsection{Fundamental and particular}

Fundamental risks are those that affect the whole, or a significant part of society, such as major natural disasters or wide-ranging political or economic factors, such as wars or recessions.

Particular risks are those which mainly affect an individual or a single firm, which may be able to control them to some extent, making a wider range of risk management options possible [4].

\subsection{The second category}

The second category contains two types of risks.

\subsubsection{Natural risks}

These risks arise from systems whose existence is beyond human agency such as: weather systems (e.g. hurricanes), geological systems (e.g. earthquakes), extra-terrestrial events (e.g. meteorite showers), and biological diversity of species on planet earth.

\subsubsection{Human risks}

These risks stem from some form of human activity such as technological and social risks that arise from human-made systems and interactions.

\subsection{Manageable risks}

Among the different types of risks, the author believes that social, political, and economic risks are more related to the management arena both at macro and micro levels, and there is a greater possibility of managing them through risk management techniques. These concepts are further elaborated in the following. 


\subsubsection{Social risks}

Social risks are determined by the value systems that are set by a particular society in a particular time. Values are enduring beliefs that specific modes of conduct or states of existence are socially preferable to their opposites [9]. Values establish the standards by which everything in society is judged [5]. Values are useful in explaining and understanding similarities and differences in behavior and in social risks. Those behaviors that are unacceptable to society generally may be categorized as social risks. In general, cultural values determine which behavior is anti-social, and may change substantially over time for a particular society, or differ between societies [3]. Social risks emanate from the threat of potentially negative interactions between groups of people espousing different cultural or religious values.

Social risks might include:

- Criminal acts (e.g. theft, robbery, sabotage)

- Civil torts (e.g. trespass, slander and libel)

- Substance abuse (e.g. drunkenness, drug-induced behaviors)

\subsubsection{Political risks}

Political risk is the possibility of unwanted consequences of political activity; it is the uncertainty associated with political activities and events [5].

In general, political risks arise out of:

1) Government action such as war and abrogation of international treaties.

2) Opposition to a government threat or action (as in case of civil disorder or industrial action).

Companies might face three types of political risk:

* Forced divestment, which occurs when a government wishes to acquire the assets of a company against the company's will (at most, with no compensation). Forced divestment can take two forms: expropriation (usually the takeover of one firm) and nationalization (usually the takeover of an entire industry) [5].

* Unwelcome regulations, which are any unexpected government-imposed requirements that make it less profitable for a company to operate in a particular location (e.g. income taxes, restrictions on reinvestment).

* Interference with operations, which is any government activity that makes it difficult to operate effectively (e.g. encouragement of unionization, voicing of negative sentiments about the managers) [5].

\subsubsection{Economic risks}

Economic and financial risks include labor or material supply issues, changes in interest rates and potential unavailability of loan finance. Some of the important risks in this category are: market risks, liquidity risks, operational and legal risks.

4.3.3.1 Market risks Market risks are the risk of loss due to changes in the prices of financial assets [6].

Using Greek letters, there are five types of market risks:

a) Delta, Gamma, Vega (or Lambda, Kappa, Tau), Theta, Rho. 
b) Delta is the risk that the value of an exposure will deteriorate as the price or value of some underlying risk factor changes, all else equal. For example, a bond is affected by changes in interest rates, so the interest rate is the risk factor [2].

c) Gamma is the risk that delta will change when the value of an underlying risk factor changes. Bond prices fall as interest rates rise, but the amount of the price change depends on the level of interest rates.

d) Vega is the risk that volatility changes in the underlying risk factor will cause a change in the value of an exposure [7]. For purchased options (longs), declines in volatility pose the risk. Less volatility means there is a smaller chance that the option held will expire profitability.

e) For options written (short), lower volatility increases the odds for an unprofitable exercise against the short to occur [7].

f) Theta measures the risk to certain exposures due only to the passage of time, insurance, for example, is an asset that decays or wastes over time. For everyday that passes on an unused insurance policy, there is one less day for the insurance contract to become valuable.

g) Rho is the risk that the interest rates, which are used to discount future cash flows in present value calculations, will change and impose unexpected losses on the firm.

Another categorization of market risks is basic and correlation risks:

a) Basic risk is the difference in price between a derivatives contract and the current spot price. The oil future basis, for example is the difference between the current price of an oil future contract and the current oil spot price.

b) Correlation risk is the risk of an unexpected change in the correlation of two factors affecting the value of a contract [2].

4.3.3.2 Liquidity risk Liquidity risk occurs in the event that cash inflows and current balances are insufficient to cover cash outflow requirements, often necessitating costly asset liquidation to generate temporary cash inflows [2].

4.3.3.3 Credit risk Credit risk is the risk of the actual or possible nonperformance by a firm. Credit risk is the possibility that counterparty may default by failing to repay its debt obligations in a timely manner [6].

4.3.3.4 Operational risk Operational risk is the risk of direct or indirect loss resulting from inadequate or failed internal processes, people and systems or from external events [7]. This risk is due to some events such as failure in computer systems, personnel quality, supervision and control. Operational risk tends to arise when personnel either fail to perform their duties or have ill-specified responsibilities [2].

4.3.3.5 Legal risk The risk that a firm will incur a loss if a contract it thought was enforceable actually is not. In addition, unexpected changes in laws and regulations can expose firms to potential loss as well [2]. 


\section{Risk management}

Risk management is the process used to systematically manage exposures to pure risk. In other words, risk management is the identification, measurement, control and financing of risks that threaten the existence, the assets, the earnings or the personnel of an organization, or the services it provides [4]. Risk managers, through application of the principles of management decision-making to the particular problems of risk, try to minimize the overall cost of risk for their organization. There are six steps in the process of risk management:

1. Identify: Identify risks before they become realities.

2. Analyze: Transform risk data into decision-making information by evaluating the probabilities, timeframes and potential impacts of each risk, then classify and prioritize them.

3. Plan: Use the decision-making information to formulate plans and contingencies for mitigating the potential impact of each risk.

4. Track: Monitor the effectiveness of those plans by reanalyzing risk data.

5. Control: Correct for deviation from the risk mitigation plans.

6. Communicate: Provide internal and external information and feedback loops to monitor changes in the risk environment [8].

Risk managers must always weigh the relative costs and benefits associated with activities that give rise to risks. They might decide to avoid the risk and decrease their chance of loss to zero, but since risks can represent either a threat or an opportunity, by avoiding all risks, the chances of gaining benefits also would decrease. When a risk is avoided, the potential benefits as well as costs are given up and this is not desirable for a company that wants to operate and survive in the environment.

Risk managers must always weigh the relative costs and benefits associated with activities that give rise to risks. They might decide to avoid the risk and decrease their chance of loss to zero, but since risks can represent either a threat or an opportunity, by avoiding all risks, the chances of gaining benefits also would decrease. When a risk is avoided, the potential benefits as well as costs are given up and this is not desirable for a company that wants to operate and survive in the environment.

\section{Conclusion}

This article commenced with a few definitions of risk, each incorporate two elements of probability of occurrence and consequences. As a matter of fact, the conceptual definition of risk varies with the perspectives. Three perspectives ranging from event-driven to financial and business risks have been described in the article. Risks may be categorized from different angles: subjective and acceptable, pure and speculative, static and dynamic, fundamental and particular, natural and human, etc. Since there is a greater possibility of managing social, political and economic risks, both at macro and micro levels, the treatment of each has been rather extensive in the article. Having an informed understanding 
about the risk and adopting an appropriate technique to minimize the cost of risk is essential for organizations in order to operate in a competitive and rapidly changing environment that is ingrained with risks.

\section{References}

[1] Trieschmann, James, S. and Sandra G. Gustavson (1995) "Risk Management \& Insurance", South-Western College Publishing, Ohio, USA.

[2] Culp, Christopher, L. (2001) "The Risk Management Process, Business Strategy and Tactics", John Wiley \& Sons, Inc. New York, USA.

[3] Edwards, Peter J. and Paul A. Bowen, (2005) "Risk Management in Project Organizations", Elsevier, Oxford, UK.

[4] Crockford, Neil (1991) "Risk Management", Witherby \& Co. Ltd, London, UK.

[5] Mendenhall, M., Punnett, B. \& Ricks, D. (1995) "Global Management", Blackwell Publishers, Cambridge, Massachusetts, USA.

[6] Lopez, Jose, A. (2007) "U.S. Supervisory Standards for Operational Risk Management", FRBSF Economic Letters, Number 2007-11, May 4.

[7] Esch, Louis, R. Kieffer \& T. Lopez (2005) "Asset and Risk Management", John Wiley \& Sons, Ltd., West Sussex, England.

[8] Pacific Asia Travel Association (2003) "Crisis: It won't happen to us", Bangkok.

[9] Rokeach, J. (1973) "The Nature of Human Values", New York: The Free Press, USA. 